\title{
Science in society, society in science
}

\section{C.A. Russell}

Between Science and Values. By Loren R. Graham. Pp.449. ISBN 0-231-05192-1. (Columbia University Press: 1981.) \$25.90, $£ 14.40$.

SCIENCE is about what is - what exists "out there" in the given world of nature. Values, however, are about what ought to be. They derive, not from ethically neutral scientific data but from the hunches of a Marx, the ambition of a Hitler, the Ten Commandments or even the Boys' Own Paper. At least, that is how the distinction is often made. On that view it is not surprising that the world between science and values has been frequently thought not to exist. Many people still believe this today, though it is a curious fact that they may arrive at such a conclusion from quite opposite directions. One group would deny the concept any validity because science and values are seen as overlapping aspects of one unified whole, each of which can expand to comprehend the other. There is no more meaningful an area "between" them than there is between the North Sea and the English Channel. Another group, however, would conceive of science and values as such different entities that they must be kept in watertight compartments and, since they must not be mixed, nothing could exist that had a little of each.

In this book such groups are labelled respectively "expansionists" and

\section{The Strain and the Bond}

She was a melancoli clone,

A prey to moods and shyness,

Who stayed at home, and grew alone $A$ virtuous $f$-minus.

She loved another from afar:

She idolized his gender.

She little knew of $\mathrm{H}$-fr

(And less of Waring blender).

Responding to her coliform, And tempted by her colihood,

The H-fr took her by storm (As willful f-rs would).

Beguiled by airy persiflage ( $A$ noxious kind of coltergeist), She caught a bout of coliphage; Succumbed to it; and lysed.

So, maidens, stay alone - and well Remaining blithe and bonny,

While other cultures go to Hell In coli matrimony.

This poem is taken from Ralph Lewin's The Biology of Algae, And Other Verses, recently reissued by University Press of America at \$6.75. Another taste of Professor Lewin's verse appears on p.506. "restrictionists". The former hold that science and values did, and do, have much in common and, while in one sense there was no separate world "between" them, they were capable of the most potent interactions that could have consequences for human history of the profoundest importance. That view, rather than the opposite restrictionist one, informs this wide-ranging analysis of scientific controversy in the twentieth century. Graham begins by an examination of relativity and quantum theory, contrasting the metaphysical attitudes of Einstein and Bohr, casting a quizzical eye at the popularizing work of Eddington, and relating to their own cultures the scientific philosophies of the Soviet physicist Fock and the German Heisenberg. In the life sciences, the speculations of Bergson and Monod are followed by the rise of behavioural psychology and ethology. The author has some extremely important things to say about the cases of sociobiology and eugenics and the problems presented in biomedical ethics.

Historians of science will find much to admire in this book, not least its careful documentation, extensive bibliography and authoritative insights into problems that are rather inaccessible (as the history of Russian physics) or else are very recent. But the issues raised are not merely of academic interest; many of them are of urgent practical importance. While the author has no panacea to offer to those facing the dilemmas posed by genetic engineering, biomedical ethics and the claims of sociobiology, he suggests many useful pointers. And one clear conclusion emerges again and again: the inadequacy of restrictionism. Historical analysis repeatedly denies us the luxury of even contemplating the emergence of either science or values without the other. Expansionism is more conformable to historical reality, though prone to abuse and perversion; one need only cite the biologies of Nazi Germany and Stalinist Russia which were "fraudulent interpretations and misuses of science that could have arisen only in their particular political and social milieux" (p. 255).

By concentrating on recent science, and especially those branches concerned with man, Graham has established his case decisively. From now on behavioural psychology, genetics and other related areas of scientific enquiry will be seen by historians as inseparably involved in valuejudgements almost from their conception onwards. This is a useful achievement, though not unexpected. It will be good news to those who over the past few years have assiduously sought to debunk "the myth of value-free science". They may, however, find some of Graham's other conclusions rather less welcome. Following
Toulmin and others he views science as a spectrum with the value-laden social and human sciences at one end, but with the largely value-free physical sciences at the other. His carefully documented casestudies offer some support for the view recently expressed (by D. M. MacKay) that the notion of universally value-laden science is an illogical extrapolation from the social sciences (where it is undoubtedly valid). Although his main purpose is to discover and demonstrate how science has affected values, the reverse process is considerably illumined by the author's narrative, and indeed the whole concept of value-laden science is complex enough to justify some analysis. It can mean at least five things.

First, it refers to values involved in choices made by individuals as to research career, subjects and modes of research, publication and so on, and by institutions as to whether to fund research and, if so, in what ways, and whether to exercise any control over it. In the last connection Graham concludes that a core-area of science should be exempt from such control and elsewhere much hard thinking needs to be done before exercising the control deemed necessary. No one would surely doubt that in this almost trivial sense science is always laden with values of individuals and society.

Second, science may be value-laden in terms of its theories. The author lists cases where the cognitive structure of science has been affected by systems as diverse as Puritanism, Naturphilosophie, monism, racism and Marxism, their distinctive values affecting the fabric of scientific thought. The different ways in which genetics developed in Germany and the Soviet Union during the 1930s illustrate particularly well the uptake of cultural values in the development of natural knowledge. His example of Copernicanism is perhaps less well-chosen since it may be doubted whether the decentralization of man was seen clearly by Copernicus as a demotion, whether Calvin ever did oppose the new system (p. 303), or even whether the "mountain of evidence" produced by Galileo was so regarded at the time (p. 362). But the essential point remains that Copernicus made a choice rather than a discovery, and that therefore values must have been present at the beginning. It is not going too far to suggest that most scientific theories are at least partly constrained by social values. That, however, is not to say that there is nothing to differentiate them in kind from (say) theories of politics or literature. The difference lies in the appeal to empirical data, and it is in this third area that the assaults on the concept of valuefree science are least successful. Given that "a real physical and biological world exists" (p. 25), empirical data and regularities will also exist independently of the ideology of the observer. Nowhere is this more true than in the physical sciences. Perhaps that is why Eddington could be so 
sure of his restrictionist position, with his limitation of science to just "pointer readings".

The application of science to technology marks a fourth opportunity to seek for values, and they are not hard to find. Decisions as to whether and how to apply science inevitably involve valuejudgements, and few would quarrel with that assertion. A point of interest that does emerge from Graham's discussion of medical ethics is that strictly scientific knowledge plays a relatively small part in creating and solving the various dilemmas. The case of amniocentesis is instructive. Medical technology, much more than scientific research, has determined the dimensions of the problem, and the social climate is even more important.

The last kind of way in which science could be said to be value-laden is in its attempted extension and application to social problems as such. In this case it is much more true that science influences values than that it reflects them in its structure and practice. And here, in example after example, Graham demonstrates how readily this happens. He traces the story from Einstein (who, though a prolific writer on social matters, denied that science was directly related to values) to the sociobiologists' conclusion that all values are under genetic control - "the ultimate expansionism". En route he has much to tell of the ways in which science was used to justify ethical norms (as with Social Darwinism and capitalism) or even to explain them. He reminds us that several key figures, as Bohr, changed their views with time; he observes that early eugenics, far from being a tool of the Right was regarded in Weimar Germany as a Leftist deviation; and he cautions us against always supposing that "science is forcing changes in our values"' (p. 267).

The author makes no attempt to conceal his own values. He emerges as a liberal and humane person, determined to see the best in ideologies with which he disagrees. Naturally some of his conclusions are highly contentious. Does it really follow, for instance, that dialectical materialism, whatever its merits, "has been damaged probably beyond the point of salvage - by the fact that it is the political doctrine of an oppressive, nondemocratic state" (p.349)? And is restrictionism always antiscientific? What about Bacon and his two books of Nature and Scripture? And who is he that shall decide the issues of human genetics "without a priori commitments" (p. 255)? Nevertheless we can be grateful for an original, provocative and at times brilliant demonstration of the relevance of historical enquiry to critical issues of our day.

C.A. Russell is Professor of History of Science and Technology at the Open University. His most recent book, Science and Social Change, will be published by Macmillan, London, later this year.

\section{The second use of nuclear weapons}

\section{Laurence Martin}

Nuclear Illusion and Reality. By Solly Zuckerman. Pp.154. UK hbk ISBN 0-00-216555-4; US 0-670-51822-0; pbk ISBN 0-00-216554-6. (Collins/Viking: 1982.) Hbk $£ 7.50, \$ 10.95$; pbk $£ 4.95$.

THE illusion which Lord Zuckerman mentions in his title, and which his book is chiefly devoted to exposing, is the idea that nuclear weapons could ever be used as a rational means of defence. A nuclear war would, he asserts, almost certainly become total, mutually annihilating, even if it began in a small way, which is itself improbable:

nuclear weapons may well be classified as strategic, theatre, and tactical, but these terms are meaningless if the use of one of them may mean the use of any.

In effect, then, nuclear weapons only serve to deter the use of nuclear weapons and Lord Zuckerman, while believing in the necessity for such deterrence, advocates what is usually called a "no first use" policy. Unilateral nuclear disarmament would expose the West to nuclear blackmail but, for all practical purposes, defence against aggression short of nuclear attacks must be provided by conventional forces. It is to those, argues Lord Zuckerman, in common with many voices now raised in the Trident debate, that our military energies should be vigorously directed. On the British nuclear force, he is a little ambivalent. He scoffs at the idea that British disarmament would serve as a useful example to others and, while regretting the resources diverted from conventional forces, he concedes the British force is an adequate deterrent to nuclear attacks on the United Kingdom. His most original reason for favouring the maintenance of the British and French forces is, however, that as small but effective deterrents they serve to demonstrate the superfluity of the huge forces maintained by the United States and Soviet Union.

There is clearly a good deal of plausibility in Lord Zuckerman's arguments and they are advanced with admirable lucidity. He pokes some shrewd holes in much that passes for strategic wisdom: pointing out for instance that those who cite the small CEP (Circular Error Probable) of missiles usually fail to consider the 50 per cent of warheads that will fall elsewhere, some with really gross errors; that tactical nuclear weapons have been widely distributed without any convincing doctrine for their use having been concocted even to the present day; that small nuclear warheads are not even very effective for many military purposes and that efforts to use them may consequently entail using large and devastating numbers. Nor can one fault his lengthy explanation of what the effects of large scale nuclear war would be, though we are perhaps not lacking in earlier expositions of this theme.

For those already immersed to some degree in the nuclear debate, however, there are two threads in Lord Zuckerman's book that may be received rather cautiously. One of particular interest to readers of this journal is Lord Zuckerman's repeated attacks on the role - the primary role it often appears - of science and scientists in promoting the "arms race". There is, of course, room for debate as to whether the international military competition that undeniably exists is so unlimited, and so useless, as the metaphor of race suggests. This debate is important, for the answer should influence our readiness to seize on such remedies as are proposed.

So far as the specific role of science is concerned in stimulating the competition, whatever its intensity, there are actually two kinds of scientists in Lord Zuckerman's world. The majority appear to be rather lower grade people, usually called "technicians", who work in military research establishments and foist innovations on the military and the politicians. There is also, however, a small elite of scientific advisers - in Britain including Lord Zuckerman himself, in the United States his friends Jerome Wiesner, Herbert York, Franklin Long and so on who see the uselessness of it all but whose advice never seems to have been taken when anything wrong was done. One can only admire the resolution with which they nevertheless clung on to the job.

The lesser kind of scientist is apparently the fundamental cause of our military predicament: "At base, the momentum of the arms race is undoubtedly fuelled by the technicians in governmental laboratories and in the industries which produce the armaments". There have been several recent studies of this problem, chiefly in the United States, and it undoubtedly deserves even more thought. Neither militarist nor keen disarmer should tolerate military developments that serve no useful strategic purpose. Doubtless some weapons do get made because they are "there" and sometimes, perhaps, a weapon emerges not as the result of a military specification but because a diversified technological process throws up the necessary components: possibly the cruise missile is such a case, coalescing from disparate developments in guidance, propulsion, image suppression and so on.

But this does not mean that the cruise missile is a useless or necessarily deplorable weapon or that its production is the result of spontaneous generation rather than rational strategic decision. Lord Zuckerman seems to regard the MIRV as such a 